\title{
Reliability Estimation of second life Battery System Power Electronic topologies for Grid Frequency Response Applications
}

\author{
N. Mukherjee*, D. Strickland, A. Cross, W. Hung ${ }^{\dagger}$ \\ *Department of Electrical, Electronic and Power Engineering, Aston University, United Kingdom \\ ${ }^{+}$National Grid Transco, United Kingdom \\ mukhern2@aston.ac.uk, d.strickland@aston.ac.uk, a.m.cross@aston.ac.uk
}

Keywords: BESS, second-life batteries, reliability, frequency response.

\begin{abstract}
This paper is part of a project which aims to research the opportunities for the re-use of batteries after their primary use in low and ultra low carbon vehicles on the electricity grid system. One potential revenue stream is to provide primary/secondary/high frequency response to National Grid through market mechanisms via DNO's or Energy service providers. Some commercial battery energy storage systems (BESS) already exist on the grid system, but these tend to use costly new or high performance batteries.
\end{abstract}

Second life batteries should be available at lower cost than new batteries but reliability becomes an important issue as individual batteries may suffer from degraded performance or failure. Therefore converter topology design could be used to influence the overall system reliability. A detailed reliability calculation of different single phase battery-to-grid converter interfacing schemes is presented. A suitable converter topology for robust and reliable BESS is recommended.

\section{Introduction}

National Grid is responsible for voltage, frequency, reserve, transmission constraints and grid recovery services. They must dispatch generating plant to match demand, provide sufficient reserve and provide frequency response capability to cover generation losses or changes to demand from that forecasted. The frequency service is automatic and is either continuous or occasional. The services are contracted out through both mandatory and competitive tendering. The frequency support is split into low frequency events (primary, secondary) and high frequency events and may be either generation or demand based. Prior to tendering a potential service provider must meet a pre-qualification assessment which includes system frequency response.

The Grid Code [1] must be adhered to when providing this service. No explicit figure is given for the reliability of the support service; however, there is a penalty impact which must be addressed if the system is too unreliable. This paper examines how 10MW at a range of reliabilities up to $96 \%$ over 5 years may be met for a distributed battery storage system. Most battery storage schemes use new batteries where the reliability of individual batteries is considered to be high. The batteries can therefore be connected in series, even though this arrangement is not the most efficient in terms of system reliability. This paper looks at using second-life batteries that have previously been utilised in electric or hybrid vehicles. These batteries should have a low cost compared with new batteries but suffer from degraded performance and reliability issues. Second-life transportation batteries utilised previously in electric and hybrid vehicles lose around $20 \%$ of their capacity before being retired from the vehicle. This leaves capacity available for a second life at a cheaper cost than a new BESS. However, the reliability of these batteries is not clear and is lower than a new battery. Manufacturers indicate that a mixture of gradual degradation and sudden failure are both possible and failure mechanisms are likely to be related to how hard the batteries were driven.

Most of the recent research into reliability of BESS has concentrated only on the reliability of the power electronic components and the power converter reliability, where the reduction of semiconductor switches and component optimisation were the key to improve reliability [2-6]. The power electronic switches were identified as the weakest link in the power circuit. The research to date has not considered the reliability of the storage source and its impact on overall system reliability. This is justifiable while the power sources are robust and their failure rates are negligible. Second-life battery failure rate cannot be ignored when calculating overall system reliability.

The objective of this paper is therefore to investigate different converter topologies that avoid large series strings of batteries. Whilst these topologies invariably lead to an increase in the number of power electronic devices in an individual converter, the higher reliability of the power electronics compared with the second-life batteries can result in a more cost-effective system. The paper describes the alternative circuit topologies for individual modules within a $10 \mathrm{MW}$ system. As such the power rating of each module may be different for each circuit. The total power output for each system (multiple modules) at fixed reliability will be the same.

The paper presents five different topologies with variations in both battery connection strategy and power electronic topologies, including some fault-tolerant or modular converter interfacing schemes [7-8] and conventional 
topologies [9]. The paper uses data from MIL-HDBK217 [10] to estimate the reliability of each unit. Sensitivity studies are undertaken to take into account the uncertainty of battery reliability. The paper determines how many parallel units are required to meet system reliability with a total output of $10 \mathrm{MW}$. The total number of units multiplied by the total number of switches in each unit provides a cost indicator for the system. The batteries are assumed to be single phase connected, however, similar results could be obtained for a 3 phase connected system.

\section{Reliability}

The methodology used to estimate reliability is based on the reliability block diagram and the technique similar to reference [4]. System reliability is computed as:

$$
R(t)=\prod_{i=1}^{n} e^{-\lambda_{i} t}
$$

$\lambda_{\mathrm{i}}$ is the failure rate of component $i$, and $n$ the total number of power stages. For a typical battery energy storage system, the different power stages with reliability block diagram (RBD) are shown in Figure 1.

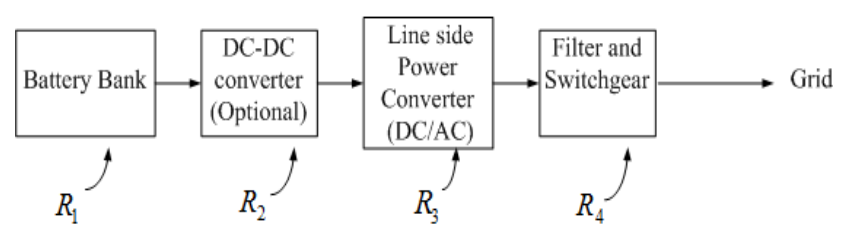

Figure 1: Power stages of conventional battery energy storage system

If there are ' $m$ ' number of modules in a system with ' $k$ ' modules having to be correctly functioning for successful operation of the system, then the system is said to have k-outof-m redundancy. The reliability of such a structure can be calculated using equation (2) where $R_{m}$ is the reliability of one module. System reliability $R(k, m)>R_{m}$ is.

$$
R(k, m)=\sum_{i=k}^{m} C_{i}^{m} R_{m}^{i}\left(1-R_{m}\right)^{m-i}
$$

The mean time to failure (MTTF) is defined by:

$$
\mathrm{MTTF}=\lambda_{p}{ }^{-1}
$$

The availability A can be calculated as

$$
A=\frac{M T T F}{M T T F+M T T R}
$$

Where MTTR is the mean time to repair. If we assume the MTTR is equal to 24 hours then the availability of a $96 \%$ reliable system over 5 years is close to unity with a downtime of approximately 1 hour within the 5 year period.

MIL-HDBK217F lists the approximate basic failure rate $\lambda_{b}$ of electronic components like capacitors, inductors, switches and diodes and also includes numerical factors for each element to take into account factors such as type of device, operating environment and power loss. The failure rate of the battery cells for initial studies was assumed to be the same as [11] $\left(\lambda_{\text {cell }}=7.7 \times 10^{-6} / \mathrm{h}\right)$. The failure rate of the controller and sensors has not been included in the analysis as these are assumed to be the same in each case and are considered negligible compared to the reliability of the power circuitry.

\section{Battery-to-grid converter interfacing schemes}

\subsection{Single-stage converter interfacing scheme}

Figure 2 shows a single-stage converter topology where a high number of battery cells $(\mathrm{N})$ are connected in series in order to create a battery bank of sufficient voltage $(\approx 300$ $400 \mathrm{~V})$ to invert straight to grid.

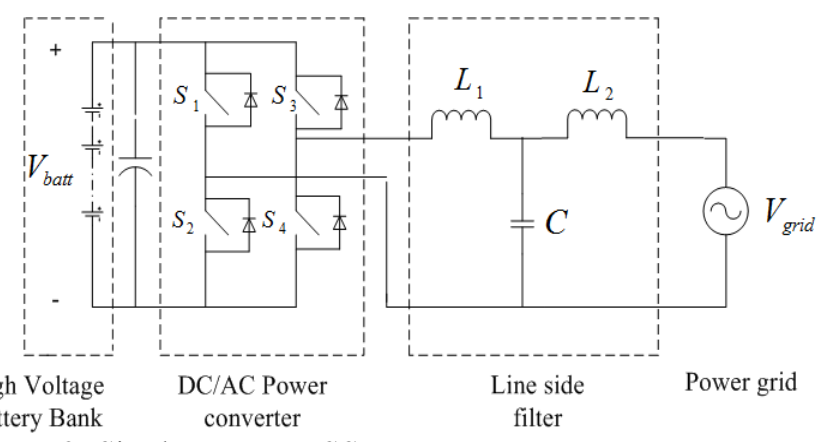

Figure 2: Single-stage BESS

The RBD for the single stage BESS is shown in Figure 3.

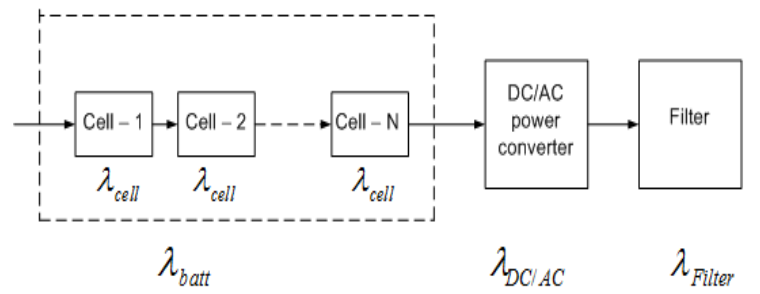

Figure 3: Reliability block diagram of a single-stage BESS

The unit failure rate of the single-stage BESS is given by equation (5). It is clear from equation (5) that the series connection of the cells means that the overall system reliability $\left(\lambda_{\mathrm{T}}\right)$ is strongly influenced by the reliability of a single cell $\left(\lambda_{\text {cell }}\right)$ and hence the total number of cells.

$$
\lambda_{T}=\left(N \lambda_{\text {cell }}\right)+\left(\lambda_{D C-A C}\right)+\left(\lambda_{\text {Filter }}\right)
$$

An advantage of this scheme is the high converter efficiency (> 95\%). In addition an open circuit failure of a single battery cell could cause entire unit failure. The battery bank voltage is created by connecting 120 cells in series (around 400V) in order to connect directly to $240 \mathrm{~V}, 50 \mathrm{~Hz} 1-\phi$ distribution supply. The LCL filter used at the output is assumed to have $\mathrm{L}_{1}=5 \mathrm{mH}, \mathrm{L}_{2}=1 \mathrm{mH}$ and $\mathrm{C}=100 \mu \mathrm{F}$. The switching frequency of the converter is taken as $5 \mathrm{KHz}$ for the purposes of the reliability estimation and it is assumed that $400 \mathrm{~V}, 30 \mathrm{~A}$ FQA30N40 MOSFET are used in the DC-AC power converter. The reliability and failure rate of each stage is calculated using equation (6) - (8) as follows.

$$
\begin{gathered}
\lambda_{D C-A C}=4 \lambda_{\text {switch }} \\
\lambda_{\text {Filter }}=2 \lambda_{\text {inductance }}+\lambda_{\text {capacitance }} \\
\lambda_{\text {batt }}=120 \lambda_{\text {cell }}
\end{gathered}
$$




\subsection{Two-stage converter interfacing scheme}

Figure 4 shows another widely used converter interfacing scheme for battery-to-grid. The main difference compared to the single-stage scheme is that a high voltage battery bus can be avoided because a DC-DC converter decouples the main DC-link of the inverter to the battery bank which ensures a stable DC-link voltage and allows the grid side power converter to operate over a wide modulation index. Battery charging current is controlled through the DC-DC converter.

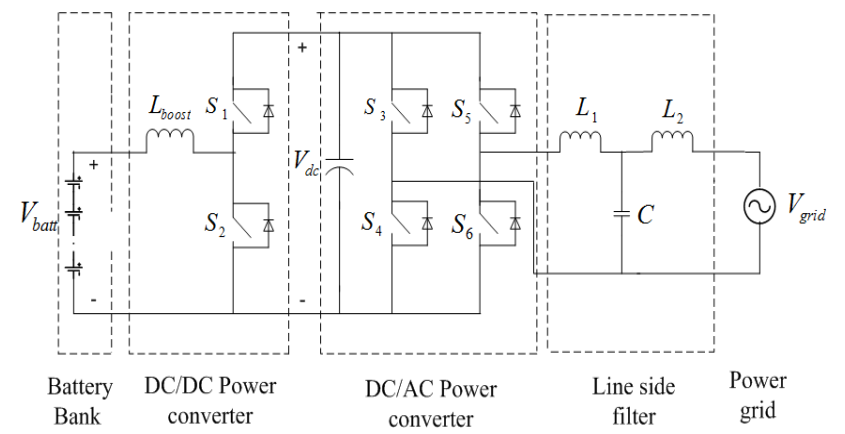

Figure 4: Two-stage BESS

The reliability block diagram (RBD) is shown in Figure 5. Equation (9) gives the unit failure rate of this scheme.

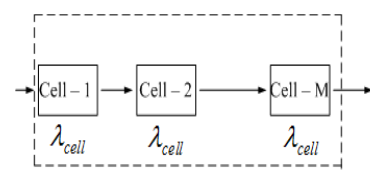

$\lambda_{\text {batt }}$

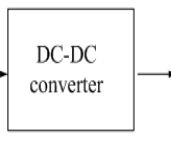

$\lambda_{D C-D C}$

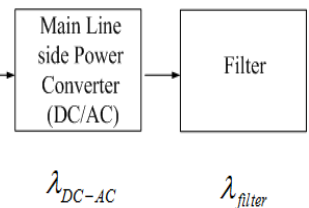

$\lambda_{\text {filter }}$
Figure 5: Reliability block diagram of a two-stage BESS

It should be noted that the number of series connected batteries cannot be reduced indefinitely because of the need to boost the voltage to a sufficient value for inverting to the grid. Very high boost ratios of the DC-DC converter would reduce the system efficiency to a very low value.

$$
\lambda_{T}=\left(N \lambda_{\text {cell }}\right)+\left(\lambda_{D C / D C}\right)+\left(\lambda_{D C / A C}\right)+\left(\lambda_{\text {Filter }}\right)
$$

The battery bank voltage is created by connecting 60 cells in series (around 200V). The DC-DC converter boosts the 200V to $400 \mathrm{~V}$ in order to form the main DC-link for the inverter. The switching frequency of the DC-DC converter is assumed to be $10 \mathrm{KHz}$. Equation (10) and equation (11) gives failure rate for DC-DC and DC-AC converters. The same switches are used for DC-AC and DC-DC converters as the single stage topology. The battery side inductance $\left(\mathrm{L}_{\text {boost }}\right)$ is assumed to be $1 \mathrm{mH}$ and DC-link capacitance is assumed to be $10 \mathrm{mF}$ for smooth and ripple free operation.

$$
\begin{aligned}
& \lambda_{D C-D C}=\lambda_{\text {inductance }}+2 \lambda_{\text {switch }} \\
& \lambda_{D C-A C}=4 \lambda_{\text {switch }}+\lambda_{\text {dc_cap }}
\end{aligned}
$$

\subsection{Two-stage configuration with cell redundancy}

This configuration is based on the two stage configuration but includes cell redundancy to enhance reliability by employing cell bypass capability through switches as shown in Figure. 6. The reliability diagram is shown in Figure 7 . The reliability calculation is almost the same as equation (9) except $\lambda_{\text {batt }}$ can be found from equation (2).

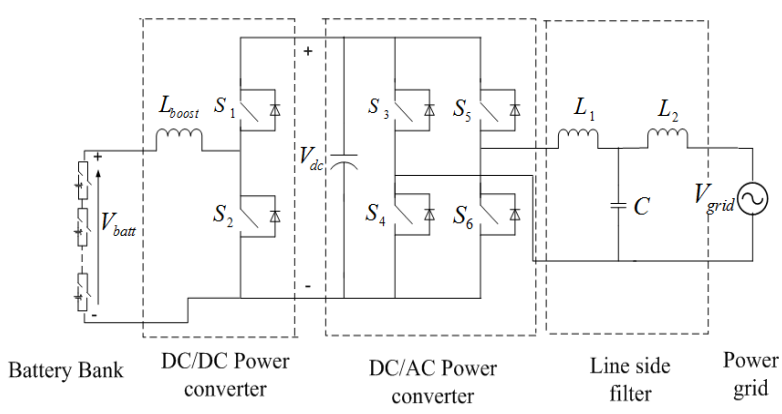

Figure. 6 Two-stage BESS with cell redundancy

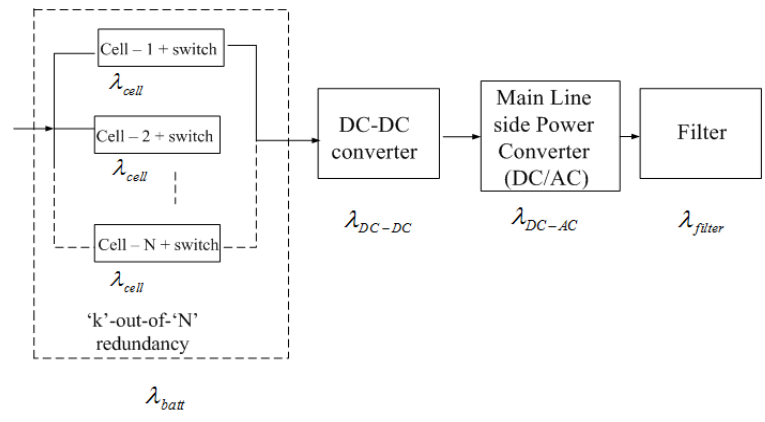

Figure 7: Reliability diagram of two-stage BESS with cell redundancy

\subsection{Three-stage converter interfacing scheme}

This scheme has been included because it is a common topology found in literature and therefore its comparison is useful. It uses a high-frequency transformer as a means of boosting the voltage from the battery as shown in Figure 8. The DC voltage of the battery side is first converted to highfrequency $\mathrm{AC}$ using an $\mathrm{H}$-bridge converter then converted back to DC before being inverted to grid through another $\mathrm{H}$ Bridge.

Isolation between the cells and grid is not required; even though this topology does provide such isolation However; there are an increased number of components compared to the two-stage configuration. The reliability block diagram (RBD) is shown in Figure 9. Equation (12) describes the unit failure rate of the BESS. $\mathrm{N}$ is the number of cells connected in series; $\lambda_{\mathrm{DAB}}$ is the failure rate of the dual H-bridges and high frequency transformer.

$$
\lambda_{T}=\left(N \lambda_{\text {cell }}\right)+\left(\lambda_{D A B}\right)+\left(\lambda_{D C-A C}\right)+\left(\lambda_{\text {Filter }}\right)
$$

The battery side voltage is assumed to be the same as the twostage configuration (200V-60 cells in series). Most of the components are the same as in two-stage BESS except the battery side MOSFETs are 200V, 30A IRFP250N. Equation (13) gives failure rate for the dual active bridges $\left(\lambda_{\mathrm{DAB}}\right)$.

$$
\lambda_{D A B}=4 \lambda_{\text {switch } 200 V}+4 \lambda_{\text {switch } 400 V}+\lambda_{H F T}
$$




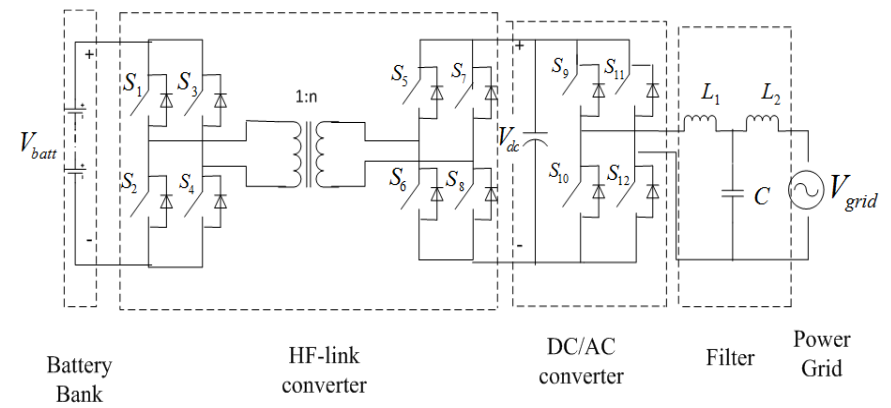

Figure 8: Three-stage HF-link converter based BESS

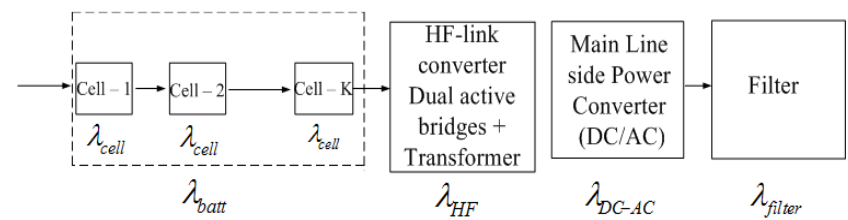

Figure 9: Reliability block diagram of a three-stage BESS

3.5 Cascaded Multilevel Converter (CMC) based topology This topology is shown in Figure 10. The main advantage of this scheme is its inherent modularity which is helpful for increasing system reliability [8]. The principle behind this reliability improvement is to avoid using a high number of series batteries as in Figure 2.

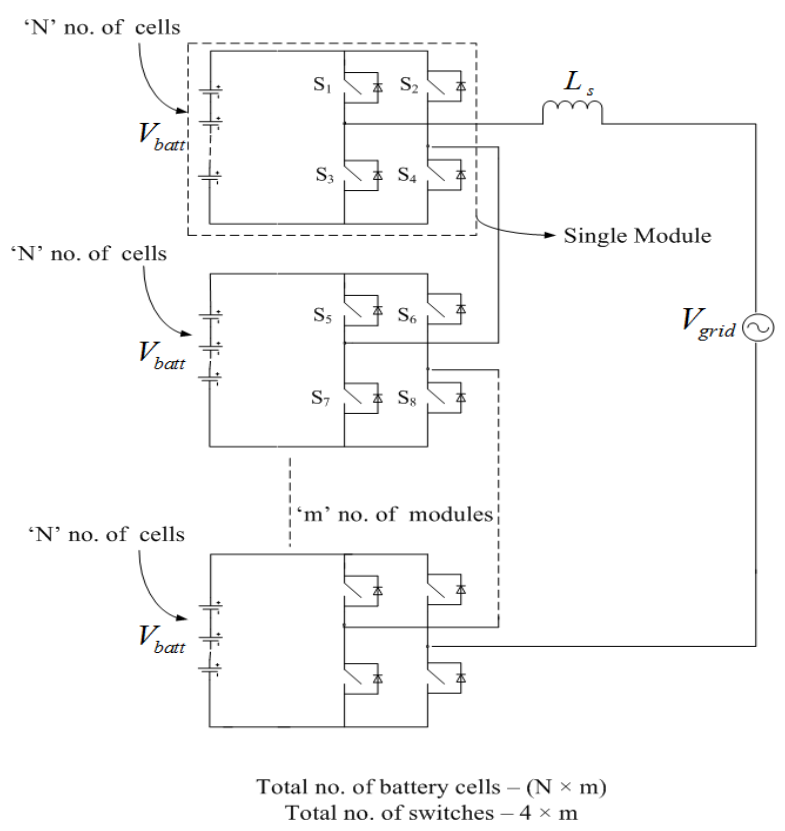

Figure 10: Conventional Cascaded Multilevel Converter (CMC) based BESS

Multiple modules (m) with less series batteries $(\mathrm{N})$ can be formed which are then connected in cascade. However, the higher number of switches and components required to improve reliability (or to create redundancy) will incur an increase in overall unit cost. The reliability block diagram (RBD) is shown in Figure 11. Equation (14) describes the unit failure rate of a single module. The number of cells (N) connected in series;

$$
\lambda_{\text {unit }}=\left(N \lambda_{\text {cell }}\right)+\left(\lambda_{D C-A C}\right)
$$

The reliability of the modular topologies is calculated in two steps: first, the reliability of each unit is calculated and then equation (2) is used to include the redundancy aspect.

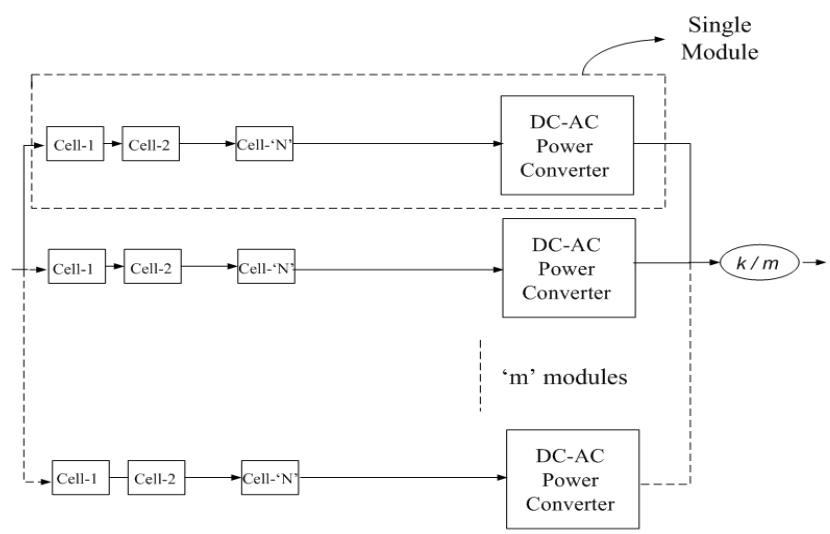

$$
\text { Reliability diagram (RBD) with }
$$

$$
\text { ' } k \text { '-out-of-'m' redundancy }
$$

Figure 11 Reliability block diagram of a conventional CMC based BESS

\subsection{Cascaded Multilevel Converter (CMC) based topology with integrated DC-DC converter}

This topology is shown in Figure 12.

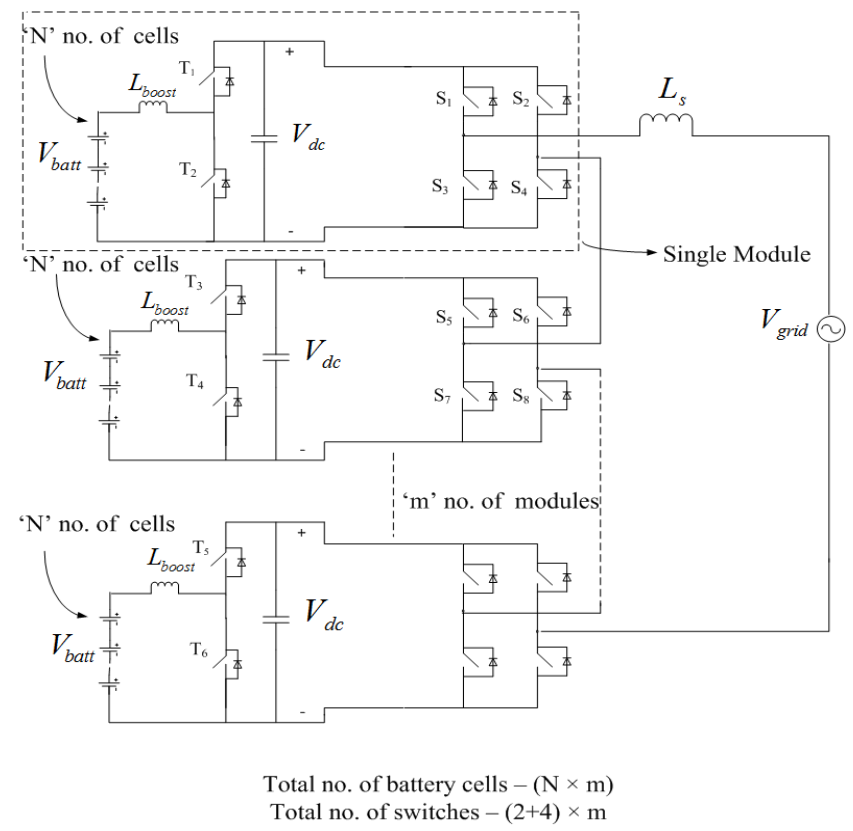

Figure 12: Cascaded Multilevel Converter (CMC) with integrated DC-DC converter BESS

The main difference compared to the previous topology is the presence of a DC- DC converter within each module which provides the opportunity to charge each module at different battery currents [12] and requires less numbers of modules 
(m) to meet the ac grid voltage for same number of series batteries (N) per module. The reliability block diagram (RBD) is shown in Fig. 12. Equation (15) describes the module failure rate. ' $\mathrm{N}$ ' is the number of cells connected in series/per module;

$$
\lambda_{\text {unit }}=\left(N \lambda_{\text {cell }}\right)+\left(\lambda_{D C-D C}\right)+\left(\lambda_{D C-A C}\right)
$$

Conventional CMC topology demands a higher number of cells to create redundancy and improve reliability, while a CMC with integrated DC-DC converter can be constructed using less battery cells.

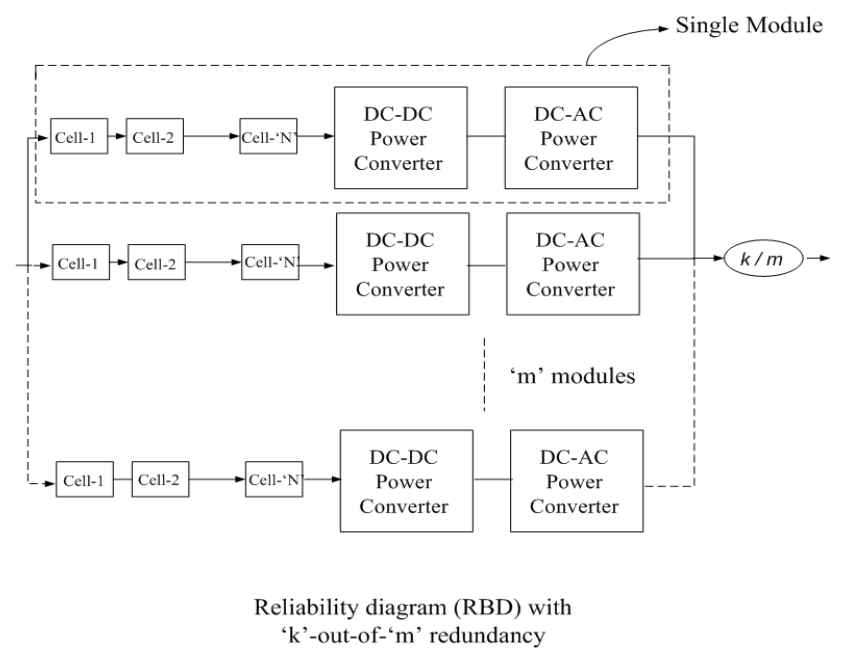

Figure 13: Reliability block diagram of a CMC with integrated DC-DC converter based BESS

\section{Reliability comparison}

Due to the requirements to have different numbers of battery cells to support different voltage levels and different levels of redundancy. The reliability of an individual unit was calculated and then the total number of such units required to meet $10 \mathrm{MW}$ at a set reliability was determined. From this figure the total number of batteries and switches to meet the overall target was compared. This allowed the total cost of a full distributed system to be estimated and compared fairly rather than basing conclusions on a single unit comparison. Each battery cell voltage was assumed to be $3.3 \mathrm{~V}$ with a 20Ahr rating.

Table 1 shows the component reliability estimation $\left(\times 10^{-6}\right)$ and the values chosen to represent the numerical factors in MIL-HDBK-217F. These values were used to calculate the total unit topology reliability as shown in Table 2 .

The reliability of the single stage converter approaches zero after 5 years. This emphasises that large numbers of series connected batteries are the dominant factor in limiting reliability. It is difficult to meet reasonable rates of reliability with series connection of batteries with no redundancy as found in conventional topologies (single/two/three stage units). Reliability could be improved by adding redundancy and monitoring banks of batteries to remove those that are faulted. For example, splitting the two stage converter into 12 units of 10 batteries each and assuming a 6 out of 12 redundancy. This is better but does not meet the performance of the CMC with integrated DC-DC Converter. A CMC with integrated DC-DC converter scheme provides similar reliability with less battery cells than a CMC converter. The modular configurations need higher numbers of switches due to the redundancy in their structure. However, the ratings of the switches can be lower.

\begin{tabular}{|c|c|c|c|c|c|c|c|c|}
\hline Component & $\lambda_{b}$ & $\pi_{T}$ & $\pi_{A}$ & $\pi_{c}$ & $\pi_{C V}$ & $\pi_{Q}$ & $\pi_{E}$ & $\lambda_{P}$ \\
\hline $\begin{array}{c}\text { Switch (400V, } \\
30 \mathrm{~A})\end{array}$ & 0.01200 & 2.1 & 10 & & & 5.5 & 1 & 1.3860 \\
\hline $\begin{array}{c}\text { Switch (200V, } \\
30 \mathrm{~A})\end{array}$ & 0.01200 & 1.4 & 10 & & & 5.5 & 1 & 0.9240 \\
\hline $\begin{array}{c}\text { Boost } \\
\text { Inductance } \\
(1 \mathrm{mH})\end{array}$ & 0.00003 & 1.8 & & & & 3 & 1 & 0.0002 \\
\hline $\begin{array}{c}\text { DC-link } \\
\text { capacitor } \\
(10 \mathrm{mF}, 400 \mathrm{~V})\end{array}$ & 0.00012 & 2.9 & & 8.3 & 1.4 & 3 & 1 & 0.0121 \\
\hline $\begin{array}{c}\text { Filter } \\
\text { Inductances } \\
(5 \mathrm{mH} \text { and } \\
1 \mathrm{mH})\end{array}$ & 0.00003 & 1.8 & & & & 3 & 1 & 0.0002 \\
\hline $\begin{array}{c}\text { Filter } \\
\text { Capacitance } \\
(100 \mu \mathrm{F})\end{array}$ & 0.00012 & 2.9 & & 2.9 & 1.4 & 3 & 1 & 0.0042 \\
\hline Transformer & 0.00540 & 3.1 & & & & 3 & 1 & 0.0502 \\
\hline
\end{tabular}

Table 1: Failure rate of components

\begin{tabular}{|c|c|c|c|c|c|}
\hline $\begin{array}{c}\text { Converter } \\
\text { Topology }\end{array}$ & $\begin{array}{c}\text { Number } \\
\text { of } \\
\text { cells, } N\end{array}$ & Redundancy & $\begin{array}{c}\text { Reliability } \\
\text { \% after 5- } \\
\text { years }\end{array}$ & $\begin{array}{c}\text { Avail- } \\
\text { ability }\end{array}$ & $\begin{array}{c}\text { Downtime } \\
\text { (days) }\end{array}$ \\
\hline Single-stage & 120 & No & $2 \times 10^{-16}$ & 0.978 & 39 \\
\hline Two-stage & 60 & No & $1.3 \times 10^{-7}$ & 0.989 & 20 \\
\hline $\begin{array}{c}\text { Two- stage } \\
\text { with } \\
\text { redundancy }\end{array}$ & 120 & $\begin{array}{c}60012 \\
\text { (k-out-of-N) }\end{array}$ & $8 \times 10^{-5}$ & 0.992 & 14 \\
\hline $\begin{array}{c}\text { Three-stage } \\
\text { Conventional } \\
\text { CMC ( N } \\
=10-\text { batteries } \\
\text { /module) }\end{array}$ & 320 & $\begin{array}{c}120032 \\
\text { (k-out-of-m) }\end{array}$ & $4 \times 10^{-9}$ & 0.987 & 24 \\
\hline $\begin{array}{c}\text { CMC with } \\
\text { integrated } \\
\text { DC-DC } \\
\text { converter (N } \\
=10-\text { batteries } \\
\text { / module) }\end{array}$ & 60 & $\begin{array}{c}3006 \\
\text { (k-out-of-m) }\end{array}$ & 0.027 & 0.996 & 8 \\
\hline
\end{tabular}

Table 2: Unit Topology reliability and availability

Comparing the performance and cost of individual units of different rating does not allow for rigorous analysis. To assist with analysis the total number of units required to meet $10 \mathrm{MW}$ of frequency support at a chosen reliability target, for example $96 \%$, has been calculated. This is done in two stages;

1. Calculate how many units are required to produce unit power at $96 \%$ reliability. Suppose, the reliability of a single unit is $\mathrm{R}_{\mathrm{m}}(<0.96)$ and ' $\mathrm{y}$ ' number of units are required in parallel to get a reliability $\mathrm{R}$ of $96 \%$. Using equation (2) for 1-out-of-y structure, allows the required 
number of units required to give the reliability through equation (16) and equation (17)

$$
\begin{aligned}
& R=1-\left(1-R_{m}\right)^{y} \\
& y=\frac{\ln (1-R)}{\ln \left(1-R_{m}\right)}
\end{aligned}
$$

2. Determine the total number of units necessary to meet $10 \mathrm{MW}$ at this level. Multiple the numbers of units by the number of switches in each unit to give an indication of total cost.

Figure 14 shows a surface plot with a cost indicator represented as the log of the total number of switches needed in a system to produce $10 \mathrm{MW} / \mathrm{hr}$ power for a given reliability and battery failure rate. Each of the surfaces refers to a different configuration. The battery failure rate has been varied between $2 \times 10^{-6} / \mathrm{h}$ and $7.7 \times 10^{-6} / \mathrm{h}$. The single stage converter offers the least value for money because of the high number of series strings of batteries. The three stage converter is always slightly less reliable than the two stage converter because of the addition of the transformer and the extra switches for what is essentially the same battery configuration. Adding redundancy to the two stage converter helps with the reliability but is not as good as adding redundancy through the use of the DC-DC and CMC configuration. The CMC configuration is not as reliable at high battery failure rates due to the series battery strings. However, as the battery failure rate drops to become close to that of the switches the CMC converter becomes more attractive and the total reliability is more dependent on the power electronics configuration and therefore this gains against the CMC with DC-DC converter which has many more switches. However, it is unlikely that battery failure rate will be this good in the short term. As battery failure rate increases it is clear that the CMC with DC-DC converter is the best topology to use to mitigate against poor battery reliability. The effect of increasing overall system reliability is to increase the number of units required.

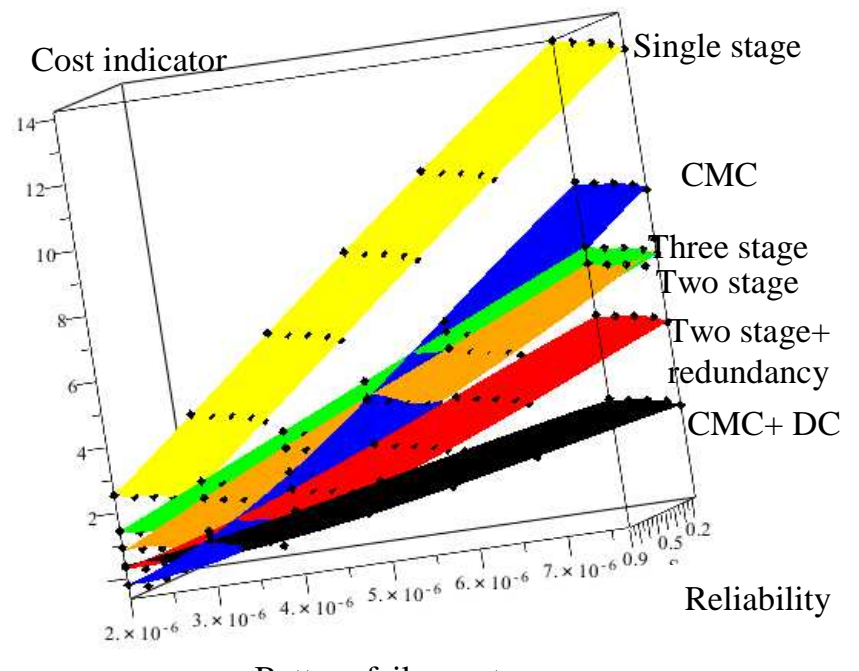

Battery failure rate

Figure 14: Total cost indicator for $10 \mathrm{MW}$ for a given reliability and battery failure rate.

\section{Conclusion}

Different battery-to-grid interfacing schemes have been compared from a reliability point of view. The results highlight the second life battery as the least reliable part of the system and minimising the number of cells connected in series is a key part of increasing system reliability of a single unit. A Cascaded Multilevel Converter with an integrated DC-DC converter scheme is the most suitable topology from among those that have been presented. This scheme requires the least number of overall components and is therefore the most cost-effective solution in spite of having more unit switches compared to conventional topologies. The future research work would consider dealing with levels of redundancy in different configurations. This paper has not considered efficiency, size, weight or bandwidth.

\section{Acknowledgements}

Dr Dani Strickland would like to thank the EPSRC (EP/1008764/1) for funding this work

\section{References}

[1] Grid Code - rev 9, Dec 2002, The National Grid Company [2] G.Chen, R.Burgos, Z.Liang, F.Lacaux, F.Wang, D. Boroyevich J.D.VanWyk, and W.G. Odendaal, "Reliability oriented design considerations for high power converter modules," IEEE Power Electron Conf., 2004, pp. 419-425.

[3] Julian, A.L.; Oriti, G "A Comparison of Redundant Inverter Topologies to improve voltage source inverter reliability" Proc. 41 ${ }^{\text {st }}$ Annual IEEE IAS, pp. 1674-1678, 2006 [4] Yi Ding; Poh Chiang Loh; Kuan Khoon Tan; Peng Wang; Feng Gao; "Reliability evaluation of three level inverters"; $25^{\text {th }}$ APEC 2010, pp: $1555-1560,2010$.

[5] Chan F, Calleja "Reliability-Oriented Assessment of a DC/DC Converter for Photovoltaic Applications" IEEE, PESC 2008, pp. 1522 - 1527

[6] Chan F, Calleja "Reliability Estimation of Three SinglePhase Topologies in Grid-Connected PV Systems" IEEE Transactions on Industrial Electronics, v58, no. 7, July 2011

[7] Chen A, Hu L, Chen L, Deng Y, and He X "A Multilevel Converter Topology With Fault-Tolerant Ability" IEEE Transactions on Power Electronics, vol. 20, no. 2, march 2005 [8] Akagi, H.; Maharjan, L.; "A battery Energy Storage system Based on a Multilevel Cascade PWM Converter" Brazilian Power Electronics Conference, 2009, pp. 9-18.

[9] Dylan C. Erb, Omer C. Onar and Khaligh A "BiDirectional Charging Topologies for Plug-in Hybrid Electric Vehicles" $25^{\text {th }}$ IEEE APEC, 2010, pp. 2066 - 2072

[10] Reliability Prediction of Electronic Equipment, Military Handbook 217-F, Dept. of Defense, Arlington, VA, 1991

[11] Xianfeng Liu, Jiyan Zou and Xu Zhang;" Investigations on the Reliability of Storage Battery Array with High Capability", International Conference on Condition Monitoring and Diagnosis, Beijing, China, April 21-24, 2008 [12] Trintis, I.; Munk-Nielsen, S.; Teodorescu, R. "Cascaded H-Bridge with Bidirectional Boost Converters for Energy Storage" 14th EPE 2011, pp. 1-9 